$\overline{\text { ECONOMICS }}$

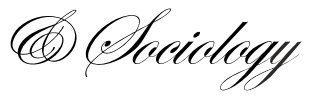

\author{
Iga Rudawska, \\ University of Szczecin, \\ Szczecin, Poland, \\ E-mail:igita@wneiz:pl
}

\author{
Jarosław J. Fedorowski, \\ University of Vermont Health \\ Network, \\ Vermont, USA, \\ Polish Hospital Federation, \\ Warsaw, Poland, \\ E-mail:jj@pfsz.org
}

Received: March, 2016

1st Revision: May, 2016

Accepted: June, 2016

DOI: $10.14254 / 2071-$

789X.2016/9-3/1

JEL Classification: I11
Rudawska, I., Fedorowski, J. J. (2016), Cross-Border Care and Cooperation, Economics and Sociology, Vol. 9, No 3, pp. 11-13. DOI: 10.14254/2071789X.2016/9-3/1

\title{
CROSS-BORDER CARE AND COOPERATION
}

\begin{abstract}
This contribution describes the results of the research conducted within the framework of "PolishGerman Health Summit 2015" project. It mainly tackles the issues concerning health economics and research dissemination in the field of cross-border care and cooperation.

Recently patient mobility, especially in the border regions, has received a huge deal of political and legal attention in the EU. However, the nature and the scale of it is more and more contested. It is argued that different stakeholders might have different interests. Supporters of the idea indicate that more intense patient mobility can introduce more competitive markets into healthcare, while skeptics argue that the health needs of the patients should be always on the top. The topics related to health economics and cross-border care became the core of this issue of Economics and Sociology. The spectrum of the covered problems range from managerial issues in health care entities, through regional approach towards cross-border care, to the issues concerning sociological aspects of patient-doctor relationship.
\end{abstract}

Keywords: health sector, health economics, cooperation.

\section{Introduction}

The movement of health professionals and patients and has highlighted appeals for better coordination of health systems and policies across the EU. Yet the absolute numbers of patient mobility within the EU remain relatively small, in some cases the most appropriate and accessible care happens to be in another Member State (Bertinato et al., 2005). Where this phenomenon does take place it raises complex questions about its impact for health systems, patients, and health professionals. In 2011 the European Union decided to tackle this issue on the legal platform.

\section{The Directive on Patients' Rights in Cross-border Healthcare}

The health systems of the EU State Members are a key component of the Union's high levels of social protection, and contribute to social justice. Although each and every EU country is responsible for ensuring its citizens the access to health care, based on the national rules, patient mobility within EU State Members is a growing phenomenon. 
It is truth that most citizens prefer to be treated near their own homes, in their native language, and with familiar procedures, but some groups of patients may decide to be treated abroad if it offers some advantage (WHO, 2014). Among these groups are:

- temporary visitors abroad who travel for work and for leisure,

- people who retire to another country,

- citizens in border regions,

- people going abroad on their own initiative,

- patients sent abroad by their home systems.

Although the absolute level of patient mobility within EU is still relatively low, the most accessible or appropriate care for certain groups, such as people living in border regions, may be in another EU Member State. It makes cross-border patient mobility within European Union high on the agenda.

In March 2011, the Council and the European Parliament adopted the Directive on Patients' Rights in Cross-border Healthcare. It was to provide a clear legal framework and to clarify the mechanisms involved in providing cross-border care (European Council, 2011). One can read that "this Directive aims to establish rules for facilitating access to safe and high-quality cross-border healthcare in the Union and to ensure patient mobility in accordance with the principles established by the Court of Justice and to promote cooperation on healthcare between Member States, whilst fully respecting the responsibilities of the Member States for the definition of social security benefits relating to health and for the organisation and delivery of healthcare and medical care and social security benefits, in particular for sickness" (European Council, 2011).

In 2013 the Directive 2011/24/EU was transposed into national law. These legislative changes that clarified patient entitlements to cross-border care, are very likely to have important impacts on national and EU-wide policies.

\section{Main objective and results of "PGHS 2015" project}

Although patients mobility across EU, especially across Poland and Germany, is not intense, there are challenges for communication and continuity of care between health professionals for those patients who do receive care abroad. The financial aspects of the patient flow constitutes also fundamental issues in cross-border cooperation. These problems there among those that have been addressed by the project entitled "Polish German Health Summit 2015" (PGHS, 2015). It was a joint initiative, undertaken by the academic and business organizations, namely University of Szczecin, University of Greifswald, German Hospital Federation and Polish Hospital Federation.

The project brings together experienced researchers from Poland and Germany, as well as business people who are active in the field of health care. It engaged altogether 86 scientists and managers, who attended 8 hours of scientific content delivered by 25 speakers. Among hot topics, transposition of the EU Cross -Border Care Directive was particularly interesting. In Germany, to date, 90 thousands of patients have been treated, what constitutes only less than $0.5 \%$ of all patients (German Hospital Federation DKG, 2015). Among patients from abroad, $60 \%$ have been from the EU member states. Germany has done a lot to facilitate influx of patients from abroad, German Hospital Federation has been the main player for the implementation of the Directive and was asked to organize National Contact Point for Cross Border Care by the German Ministry of Health. The contact point has been established by means of an excellent internet site containing lots of information in English and providing references as well as contact information. German contact point is a good example of proactive policy of an EU member state in implementation of the EU Directive. 
On the Polish side, things are not that well developed. National contact point has been established by the National Health Fund rather than the national hospital federation. The web site provides only basic information in English and most of references are in Polish. The user friendliness of the contact point is below expectations. The actual data about patients coming to Poland from another EU member state for cross border care under the CBCD regulations is not available.

Another subject that has been examined within the "PGHS 2015" project was crossborder care at the local level that is in the regions immediately adjacent to national borders. German patients are receiving care in nearby Polish regions for their dental and aesthetic medicine needs, while Polish patients are going across the border for obstetrics and surgical care. The fact that many close to the border hospitals in Germany employ doctors from Poland, mitigates language barrier. Those are observations from Meklemburg and Zachodniopomorskie border regions from Germany and Poland, respectively. Participants noted that local patient traffic is a substantial part of cross border care in the EU.

Another very interesting point in the discussions undertaken under project umbrella was about optimization of utilization of operating rooms in Germany. The problem of many small hospitals with insufficient coordination of surgical (operating room) use is generating financial losses. An innovative analysis of the problem has been developed with prospect to improve the situation in the near future. The initiative comes from the University of Greifswald but is intended to be a joint science to business endeavour.

\section{Conclusions}

The presented issue of "Economics and Sociology" journal is based on the outcomes of the research conducted by the academics from different EU countries, with Poland and Germany among them. They represent economic, managerial and sociological approach. Selected papers refer to risk management, compliance, hospital governance, hospital-acquired infections, dialysis-economic challenges of different treatment alternatives, hospital group purchasing, IT solutions, hospital logistics, managed care, long term care, doctor-patient relationship, tax laws pertinent to healthcare, hospital strategy and development.

The dissemination on the cross-border care conducted within the framework of the "PGHS2015" project examined the key challenges faced by the EU Member States in the field of heath sector. The results of this dissemination and its core sectoral implications might be of special interests both for academics in the EU, as well as for the policy makers in the area of health care.

\section{References}

Bertinato, L., Busse, R., Fahy, N., et al. (2005), Cross-Border Health Care in Europe, Policy Brief, Brussels, World Health Organization.

Directive 2011/24/EU of the European Parliament and of the Council of 9 March 2011, http://eur-lex.europa.eu/legal-content/EN/ALL/?uri=CELEX\%3A32011L0024 (access: 21/04/2016).

Footman, K., Knai, C., Baeten, R., Glonti, K., McKee, M. (2014), Cross-border health care in Europe, Policy Summary 14, European Observatory on Health Systems and Policies, World http://www.euro.who.int/_data/assets/pdf_file/0009/263538/Cross-border-health-carein-Europe-Eng.pdf?ua=1 (access: 21/04/2016). 